\title{
El coronavirus y el estado fallido en salud
}

\author{
Diego Herrera [1] \\ 1. Saludesa, Ecuador
}

Doi: https://doi.org/10.23936/pfr.v5i3.174

PRÁCTICA FAMILIAR RURAL | Vol.5 | No.3 | Noviembre 2020 | Recibido: 15/11/2020 | Aprobado: 17/11/2020

\author{
Cómo citar este artículo \\ Herrera, D. El coronavirus y el estado fallido en salud. \\ Práctica Familiar Rural. 2020 noviembre; 5(3).
}

\section{Resumen}

El Virus del Covid ha puesto de cabeza al mundo y a los supuestos que le daban seguridad a la democracia y a los Estados Nación, la debilidad de las respuestas gubernamentales, para enfrentar la epidemia, han dado pie a un nuevo calificativo para los gobiernos de varios países del mundo, el de "Estado Fallido".

Palabras clave: coronavirus, política sanitaria, estado fallido.

The coronavirus and the failed state in health

Abstract

The Covid Virus has turned the world upside down and the assumptions that gave security to democracy and the nation states, the weakness of government responses to face the 
epidemic, have given rise to a new qualifier for the governments of several countries of the world, that of "Failed State".

Keywords: coronavirus, health policy, failed state.

Estado Fallido es un término que califica a un Estado débil, en el cual el gobierno central tiene poco control práctico sobre su territorio; podría decirse que un Estado es fallido o comienza a fallar cuando las estructuras internas no son funcionales. Así, se dirá que un Estado falla cuando, las políticas sociales se hacen ineficaces para responder a las demandas de la comunidad, el régimen político se degenera y deja de representar o servir a las personas, la economía es obsoleta y genera todo tipo de crisis, el desarrollo humano y la seguridad humana no se garantizan o son precarios (1).

El número de casos de COVID-19 comenzó a incrementar drásticamente en marzo del 2020 en Guayaquil. El Ecuador y el sistema de salud pública no estaban preparados para responder a esta emergencia. Poco tiempo atrás se habían hecho despidos y se había recortado el presupuestario. Había una reducción del 36\% del presupuesto (66 millones de dólares menos que en el 2016), lo que implicó recortes en nómina de recursos humanos, así como otros gastos en los Hospitales; también hubo limitación de las transferencias que se hacían a los prestadores privados (Red Complementaria de Salud), a quienes mantenía impagos por varios meses (2).

Los hospitales se saturaron rápidamente y las salas que no estaban diseñadas para aislamiento masivo, colapsaron. La escasez de equipos de bioseguridad para el personal sanitario fue el primer escándalo mediático. Una fuente de noticias describió que, a pesar de las alertas tempranas de pandemia, el gobierno central no compró insumos médicos entre enero y marzo. A partir de enero, los proveedores de suministros médicos solicitaron a los funcionarios de salud que comenzaran los procesos contractuales para solicitar equipos de protección y materiales de prueba, ya que este proceso requiere muchas semanas. En abril no había stock de insumos de seguridad en el suministro central, contradiciendo las declaraciones hechas por el ministro de salud, en marzo del 2020, quien aseguró a la prensa, que los hospitales cuentan con los medicamentos y suministros para enfrentar la pandemia: "Tenemos suficientes y vienen más" (3).

La comunicación oficial se ha dedicado a minimizar los datos, y la parsimonia de sus declaraciones nos recuerda al "terror psicológico" con el que Hitchcock nos introducía en sus historias de suspenso. Un terrible ejemplo de esto ha sido el manejo mediático a los contagios entre los profesionales de la salud. El $40 \%$ de los trabajadores de la salud en Guayaquil se infectaron al principio del brote. Para el 14 de junio, la Federación Médica Ecuatoriana estimó que a nivel nacional fallecieron más de 120 médicos atendiendo a pacientes con COVID-19 (4). Las desventuradas declaraciones del ministro de salud han sido que "los profesionales se contagiaron en la comunidad y llevaron el virus a los hospitales", desatendiendo una verdad que ha sido solapada hasta el momento: el virus había llegado antes de lo establecido en la declaración de la emergencia sanitaria. 
Por otro lado, aquellos políticos que antes defendieron las políticas de reducción del Estado, reorganizaron su discurso en torno a la necesaria intervención estatal, renegaron de los programas de austeridad que golpearon de lleno la salud pública. Incluso en los países del Norte se instauró una campaña, centrada ingenuamente, en la compra de respiradores para las unidades de cuidados intensivos como una medida trascendental para enfrentar la crisis. Esta postura es miope no solo porque reduce la solución de la crisis al equipamiento y abastecimiento ventiladores mecánicos en el sistema nacional de salud, sino porque se desentiende de muchos otros problemas especialmente sociales que influyeron en la alta transmisibilidad del virus.

A pesar de las noticias de compras y donaciones de ventiladores, un informe reciente sobre la adquisición de estos equipos en países de América Latina colocó a Ecuador al final de la lista con 57 unidades compradas durante el período crítico. Paraguay, con menos de la mitad de la población de Ecuador, le siguió con 63 ventiladores comprados. En un momento dado, el gobierno informaba menos de 200 muertes totales de COVID-19 confirmadas oficialmente, mientras que la policía retiraba de la ciudad más de 100 cadáveres diariamente. En el pico del brote de Guayaquil, ocurrieron más de 400 muertes en un solo día.

A partir de febrero de este año, el brote de Covid-19, el miedo provocado por la emergencia sanitaria y los escándalos de corrupción se convirtieron en el escenario perfecto para seguir implementando el ajuste estructural.

Desde el 17 de marzo de 2020 rigió un estado de excepción que duró 180 días hasta el 13 de septiembre. Desde el 25 de marzo, el toque de queda se amplió a 15 horas diarias, pero se redujo paulatinamente a mediados de mayo y de manera diferenciada en los 221 cantones del Ecuador, hasta cesar con el fin del estado de excepción. Durante este tiempo, la emergencia sanitaria no supuso un cambio de timón para preservar la salud integral y la situación social y económica de la población. Todo lo contrario, su ejecución rápidamente se adaptó al guion neoliberal, reduciendo los pocos recursos existentes para la política social, incluidos los de la gestión de la pandemia, pero priorizando el pago de la deuda externa y el desmantelamiento de la institucionalidad (5).

Los medios de comunicación publicaron historias sobre modelos matemáticos que se suponía erróneamente, calculaban con precisión el número de muertes que se producirían. Era clara la incapacidad de establecer una vocería nacional legítima que pudiera responder de alguna manera a la avalancha de información relacionada con la emergencia sanitaria, la incertidumbre y el pánico social. En medio de todo este "zafarrancho", algunos médicos del ministerio de salud, alcaldes de varias ciudades y más de 10 obispos, contradijeron las normativas nacionales, y entregaron oxido de cloro e ivermectina a la ciudadanía como una medida "preventiva y terapéutica" (6).

A nivel nacional, el exceso de fallecidos hasta octubre del 2020 fue de 36,351 personas por encima del promedio histórico de los tres años previos y la tasa de mortalidad es de 207.6 por cada 100,000 habitantes. Según el periódico británico "Financial Times", en septiembre Ecuador registró la segunda tasa más alta de exceso de muertes después de Perú. Al mismo tiempo, el Gobierno Nacional reportaba 12,357 personas fallecidas por Covid-19, con 
una tasa de mortalidad de 70.6 por cada 100,000 habitantes, lo que ubica a Ecuador $7^{\circ}$ en el mundo y $4^{\circ}$ en América, después de Perú, Bolivia y Brasil, resaltando el "modelo exitoso" de contención que estaba aplicando, e invitando a expertos internacionales a compartir este modelo (5).

La Red Publica Integral de Salud (RPIS), no garantizó el acceso a los servicios de salud para la población, a tal punto que se creó una "lista de espera para Unidad de Cuidados Intensivos". El sistema de salud no solo estaba sobresaturado, sino que en el momento más crítico que se recuerde en la historia de la salud, excluyó a los prestadores privados para la atención de los pacientes con Covid-19.

La calidad de atención de los hospitales, que hace solo dos años había logrado la acreditación, con la ONG canadiense "Accreditation Canada International", también está en duda. Todos estos hospitales, para las fechas de la acreditación, ya tenían incrustadas mafias corruptas en su sistema de compras, las cuales pasaron desapercibidas durante todo este proceso. La ONG canadiense, tampoco descubrió, la falta de liderazgo y ausencia de rendición de cuentas y transparencia, en las 44 instituciones hospitalarias acreditadas. A nuestro criterio, estos problemas pesan más sobre los resultados negativos de la calidad que cualquier deficiencia técnica de un sistema de salud (10).

La corrupción combinada con la ausencia de liderazgo y la falta de compromiso de los funcionarios de salud (aquellos que han perdido el enfoque en el paciente) describe el Estado fallido en Salud que se desnudó con esta epidemia. Los medios de comunicación y de las sociedades científicas han dado la espalda a esta realidad, la han ignorado y la reemplazaron con publicidad enfocada en responsabilidad y disciplina social. Para que el mensaje sea impactante y políticamente aceptado por las élites, la propagación de la enfermedad ha sido descrita, bajo la "metáfora de la otroredad social", como consecuencia de la significación anterior, las enfermedades pertenecen a los otros, a los no semejantes, a los foráneos, a los extranjeros, a los salvajes (8).

El discurso oficial, culpabiliza a la "mala educación" y "malas costumbres" de los pobres de nuestros países, por la propagación del virus, con un discurso ingenuo y conservador, niegan las desigualdades de las sociedades latinoamericanas y exigen una respuesta homogénea en una sociedad desigual y heterogénea, que se ve ahora dividida entre "los que si se cuidan" y "los que no se cuidan". Para ejemplificar la ingenuidad de la universalización de las recomendaciones basta revisar algunos datos olvidados. En Ecuador, solo 5 de cada10 personas tienen empleo pleno. Pese a que lavarse las manos parecería una actividad sencilla para combatir la pandemia, 2 de cada 10 personas no tienen acceso al agua potable dentro de su vivienda. A estos se suma que 3 de cada 10 familias en el país viven hacinadas, es decir, que más de tres personas duermen en una habitación sin ventilación, donde también cocinan (5).

Los obreros, los empleados con sueldo básico, las trabajadoras domésticas, están obligados a utilizar el deteriorado transporte público para llegar a sus lugares de trabajo; en estos buses, no es posible mantener el distanciamiento social. Es trágico que el pensamiento disyuntivo y reductor reine de modo dominante en nuestra civilización y defina los comandos tanto en la política como en la economía. Esta formidable carencia ha conducido tanto a errores de diagnóstico y de prevención como también a decisiones aberrantes. 
Para Edgar Morin, filósofo francés, la obsesión por la rentabilidad, de quienes nos dominan y dirigen, ha conducido a economías culpables, que se demuestran en el manejo de los hospitales y la "bipolaridad" en el ambivalente mensaje de abrir las economías y al mismo tiempo mantener las medidas de prevención. La locura eufórica del "transhumanismo", lleva al paroxismo el mito de la necesidad histórica del progreso acompañado del mito del dominio por parte del hombre no sólo de la naturaleza sino también de su destino, mito que predice el acceso del hombre a la inmortalidad y el control de todo lo que sucede en el mundo. En realidad, somos jugadores/jugados, poseedores/poseídos, poderosos/débiles. Si podemos retardar la muerte por el envejecimiento, no podremos jamás eliminar los accidentes mortales en los que nuestros cuerpos serán aplastados, nunca podremos deshacernos de las bacterias y los virus que sin cesar se auto-modifican para resistir a los remedios, antibióticos, antivirus y vacunas (9).

\section{Referencias bibliográficas}

1. Zapata, J. La teoría del estado fallido: entre aproximaciones y disensos. rev.relac.int.estrateg.segur. [online]. 2014, vol.9, n.1 [cited 2020-1113], pp.87-110. Available from: <http://www.scielo.org.co/scielo.php? script $=$ sci_arttext\&pid=S190930632014000100005\&lng=en\&nrm=iso $>$. ISSN 1909-3063.

2. Instituto de Investigaciones Económicas, Los recortes cobran factura al Ecuador: La inversión en salud se redujó un $36 \%$ en 2019. Universiadad Central del Ecuador.

3. Ministro de Salud: 'Tenemos un suficiente número de trajes (de bioseguridad) para Guayaquil' . El Comercio [Internet]. 2020 [citado 15 noviembre 2020];. Disponible en: https://www.elcomercio.com/actualidad/guayas-ministerio-saludcadena-zevallos.html

4. La Federación Médica Ecuatoriana está de luto desde que inició la pandemia de CoVID19. Edición Médica [Internet]. 2020 [citado 15 noviembre 2020];. Disponible en: https://www.edicionmedica.ec/secciones/profesionales/la-federacionmedica-ecuatoriana-esta-de-luto-desde-que-inicio-la-pandemia-decovid19-96001

5. Hurtado F, Velasco M. La pandemia en Ecuador. Desigualdades, impactos y desafíos. Quito: Observatorio Social del Ecuador y FESIldis; 2020.

6. Uso de dióxido de cloro crea polémica. La Hora [Internet]. 2020 [citado 15 noviembre 2020];. Disponible en: https://www.lahora.com.ec/santodomingo/noticia/1102320101/uso-dedioxido-de-cloro-crea-polemica-

7. Uso de dióxido de cloro crea polémica. La Hora [Internet]. 2020 [citado 15 noviembre 2020];. Disponible en: https://www.lahora.com.ec/santodomingo/noticia/1102320101/uso-dedioxido-de-cloro-crea-polemica-

8. Herrera, D., Troya, C., Gaus, D. COVID-19 in Ecuador: Imported Control Strategies without Context in a Challenged Healthcare System. Am. J. Trop. Med. Hyg., 00(0), 2020, pp. 1-2

9. Del Río, A. Rico, M. La enfermedad como otredad: Las metáforas dominantes a partir de las prácticas artísticas visuales Revista de 
Antropología Iberoamericana www.aibr.org Volumen 14 Número 2 Mayo - Agosto 2019

10. Morin, E. Festival de incertidumbres, Publicado el día 21 de abril de 2020 en la serie Tracts de crise de ediciones Gallimard con el número 54 (https://tracts.gallimard.fr/fr/products/tracts-decrise-n-54-un-festivald-incertitudes 